\title{
TRANSFERÊNCIAS FEDERAIS ATRAVÉS DOS BLOCOS DE FINANCIAMENTO EM SAÚDE, NA MACRORREGIÃO SUDOESTE DA BAHIA
}

\author{
Ilane Moreira Figueredo'; Marcia Reis Rocha Rosa²; Thereza Cristina Bahia Coelho ${ }^{3}$; \\ Andrei Souza Teles ${ }^{4}$; Milla Pauline da Silva Ferreira ${ }^{5}$; Júlio Moraes Brito Regis ${ }^{6}$; \\ Guilherme Braga Alencar de Novais ${ }^{7}$ e Valéria Santos Santana ${ }^{8}$ \\ 1. Bolsista FAPESB, Graduanda em Medicina, Universidade Estadual de Feira de Santana, e-mail: \\ ilanemoreira@outlook.com \\ 2. Orientadora, Departamento de Saúde, Universidade Estadual de Feira de Santana, e-mail: marciareisrosa@ yahoo.com.br \\ 3. Participante do Núcleo de Saúde Coletiva, Departamento de Saúde, Universidade Estadual de Feira de Santana, e-mail: \\ tcuide@yahoo.com.br \\ 4. Participante do Núcleo de Saúde Coletiva, Departamento de Saúde, Universidade Estadual de Feira de Santana, e-mail: \\ stdrei@hotmail.com \\ 5. Participante do Núcleo de Saúde Coletiva, Departamento de Saúde, Universidade Estadual de Feira de Santana, e-mail: \\ millapauline@ hotmail.com \\ 6. Participante do Núcleo de Saúde Coletiva, Departamento de Saúde, Universidade Estadual de Feira de Santana, e-mail: \\ imbreges@ hotmail.com \\ 7. Participante do Núcleo de Saúde Coletiva, Departamento de Saúde, Universidade Estadual de Feira de Santana, e-mail: \\ guilhermea15@hotmail.com \\ 8. Participante do Núcleo de Saúde Coletiva, Departamento de Saúde, Universidade Estadual de Feira de Santana, e-mail: \\ valer.ss1727@gmail.com
}

PALAVRAS-CHAVE: financiamento, gastos em saúde, blocos de financiamento.

\section{INTRODUÇÃO E JUSTIFICATIVA}

A Constituição Federal de 1988 instituiu o Sistema Único de Saúde (SUS) procurando assegurar aos cidadãos brasileiros o direito à saúde como dever do Estado (Teles, 2016). No entanto, o financiamento tem se mostrado insuficiente para assegurar recursos adequados e estáveis para a manutenção da estrutura desse sistema (Paim, 2011).

Com aprovação da Emenda Constitucional $n^{0}$ 29, estados e municípios tiveram sua participação no financiamento da saúde vinculada à sua receita tributária, ficando obrigados a aplicar $12 \%$ e $15 \%$ da receita de impostos e transferências constitucionais e legais, respectivamente (Piola, 2016). Enquanto a União ficou responsável por aplicar, anualmente, em ações e serviços de saúde, o montante correspondente ao valor da Receita Corrente Líquida (RCL) do respectivo exercício financeiro, de forma escalonada, em cinco anos (Mazon, 2018). Contudo, com o novo regime fiscal, instituído pela Emenda Constitucional $n^{\circ}$ 95, que congela o gasto primário federal por 20 anos, a partir de 2017, agravará ainda mais o subfinanciamento crônico do SUS.

Devido à excessiva fragmentação de programas e serviços de saúde, que dificultava a atuação de gestores, bem como o desempenho das próprias atividades de saúde, em 29 de janeiro de 2007 foi implantada a Portaria GM/MS no 204 que regulamentou o financiamento e as transferências de recursos federais para as atividades de saúde na forma de cinco blocos: 1) Atenção Básica (AB); 2) Atenção Média e de Alta Complexidade Ambulatorial e Hospitalar (MAC); 3) Vigilância em Saúde; 4) Assistência Farmacêutica; 5) Gestão do SUS (Teles, 2016). Em 2009, foi inserido pela Portaria $n^{\circ} 837$, o bloco de Investimentos na Rede de Serviços de Saúde.

Em 2017, a Portaria no 3.992 do Ministério da Saúde, extinguiu os blocos de financiamento citados anteriormente e instituiu apenas dois: um de custeio, que concentra a quase totalidade dos recursos federais; e outro de investimentos. Essa medida, de acordo com 
o Centro de Estudos Estratégicos da Fiocruz, anteveem a queda dos níveis de investimento na atenção básica e na vigilância em saúde que, desde a criação dos seis blocos vinham sendo ampliados.

O problema do gasto em saúde permanece ainda como significativo entrave a ser superado a fim de que a garantia de acesso universal e atendimento integral, realmente, possa se concretizar (Teles, 2016). Isso porque além da escassez de recursos e da sobrecarga dos municípios como citado por Mazon, há outros impasses trazidos por Teles que são: a falta de eficiência e efetividade em sua aplicação, iniquidades na alocação de recursos, inadequada priorização e a malversação dos gastos. Além disso, os gastos em saúde são afetados pelo aumento e envelhecimento da população e pela incorporação crescente de tecnologias médicas.

Portanto, conhecer de forma mais profunda como o financiamento do SUS se organiza permite, aos gestores, adequado planejamento e controle na execução do gasto público; a sociedade, acompanhar e fiscalizar a implementação da política pública de saúde para defesa e construção do SUS que, de fato, atenda aos preceitos de equidade, igualdade e integralidade.

O objetivo deste estudo foi analisar as transferências federais realizadas, na forma de blocos de financiamento, para o SUS, nos municípios da macrorregião Sudoeste do estado da Bahia, no período de 2010 a 2015.

\section{MATERIAL E MÉTODOS OU METODOLOGIA (ou equivalente)}

Trata-se de um estudo quantitativo em uma perspectiva descritiva, comparativa e retrospectiva, no qual se analisou as transferências federais para o SUS nos municípios da macrorregião Sudoeste do estado da Bahia.

A macrorregião Suedoeste é composta por 73 municípios distribuídos em quatro microrregiões de saúde: Brumado, Guanambi, Itapetinga e Vitória da Conquista. A macrorregião Sudoeste possuía uma população total de 1.713.082 habitantes.

O modelo de Contas Nacionais de Saúde (National Health Accounts) - NHA, trata-se de uma ferramenta de síntese, descrição e análise das informações financeiras que objetiva melhorar a performance do sistema de saúde. Mensura os gastos em saúde utilizando uma matriz com quatro categorias básicas da atenção à saúde:

1- Fontes de Financiamento: são responsáveis por fornecer as verbas para o setor da saúde, tais como os recursos de arrecadação tributária federal, estadual e municipal;

2- Agentes de Financiamento: são os receptores intermediários das verbas de fontes de financiamento e as usam para pagar serviços de saúde e produtos (medicamentos, remédios etc);

3- Provedores: são os receptores finais das verbas de cuidados com a saúde. Distribuem os serviços de saúde para a população, ou seja, os hospitais, as clínicas e os postos de saúde;

4- Atividades: referem-se às ações e serviços que os provedores oferecem com seus recursos, por exemplo, curativos, cuidados de enfermagem, insumos médicos, dentre outros.

Estas categorias orientam a montagem das tabelas e guiam, estruturalmente, a análise. A identificação detalhada do fluxo de recursos permite identificar como cada serviço é financiado, ou dito de outra maneira, torna-se possível saber quem gasta em saúde, como e quanto.

A partir deste modelo foi montado a Tabela 1 (Fontes X Agentes de Financiamento) utilizando-se do programa Excel para formar matrizes contábeis (receita $\mathrm{X}$ despesas), as quais organizarão os dados (valores) coletados nos sistemas de informação, tais como o Sistema de Informações sobre Orçamentos Públicos de Saúde (SIOPS), o Departamento de Informática do SUS (DATASUS) e o sistema de informação mantido pelo Fundo Nacional de Saúde 
(FNS), todos disponíveis na internet. Os valores alcançados via tabulação foram transformados em gráficos e tabelas menores que permitiram variáveis análises.

Em seguida, foi realizado o deflacionamento dos valores para melhor comparação entre os anos estudados. A partir da análise dos dados das transferências federais realizadas através dos blocos de financiamento em saúde, foi possível traçar um perfil de como as receitas são distribuídas para cada município, cada região de saúde e na macrorregião como um todo. Além disso, as tabelas se constituíram em uma base de dados confiáveis, para a realização de analises secundárias, estatisticamente, mais sofisticadas, a serem exploradas em outros estudos.

\section{RESULTADOS E/OU DISCUSSÃO (ou Análise e discussão dos resultados)}

Durante o período estudado o financiamento federal, através dos blocos de financiamento, para os municípios da macrorregião Sudoeste do estado da Bahia sofreu um aumento gradual. Em valores nominais, ou seja, não deflacionados, essas transferências totalizaram $\mathrm{R} \$$ 2.105.206.122,59, ou $\mathrm{R} \$ 1$ 1.756.628.010,79 quando eliminamos o efeito da inflação. Quando comparamos cada ano do estudo, verifica-se que houve um aumento de, aproximadamente, $16,63 \%$ em valores reais, dos repasses durante todo o período, uma vez que os repasses passaram de $\mathrm{R} \$ 260.523 .509,67$, em 2010, para $\mathrm{R} \$ \mathrm{R} \$ 303.865 .526,49$, no ano 2015 , mesmo com a redução real de $7,81 \%$ dos repasses entre os anos de 2014 e 2015 . O ano de 2015 apresentou o maior índice de inflação do período, 10,67\%, o que explica em parte a redução no valor real dos repasses neste ano. Em valores reais, o ano que apresentou o maior montante de transferências foi o ano de 2014, com um valor real total de $\mathrm{R} \$$ 329.615.779,18. O crescimento mais expressivo do período foi registrado entre os anos de 2013 e 2014, quando os repasses aumentaram em 17,14\%.

Quando comparamos a participação da esfera federal em relação às outras esferas (municipal e estadual), na composição da receita dos municípios para a saúde, notamos uma diminuição da sua participação no montante total. Durante o período, a receita federal passou de 53,98\% da receita total desses municípios em 2010, para 52,63\% em 2015, representando uma redução de $1,35 \%$. A participação da esfera federal manteve uma porcentagem relativamente constante para cada ano estudado.

Analisando-se cada bloco de financiamento separadamente, é possível notar que o bloco da Atenção Básica recebeu um montante de R \$ 848.653.859,71, o que correspondeu a $46,41 \%$ do total alocado para os blocos de financiamento, de 2010 a 2015, correspondendo, assim, ao bloco que recebeu o maior montante de recursos federais. Dentro do bloco de Atenção Básica, o Piso de Atenção Básica Fixo (PAB FIXO) e o Programa de Saúde da Família, corresponderam por $56,82 \%$ do valor total, representando, assim, as principais fontes de recursos financeiros para a Atenção Básica dos municípios da macrorregião Sudoeste.

$\mathrm{O}$ segundo bloco de financiamento que mais recebeu recursos federais foi o de Atenção de Média e Alta Complexidade Ambulatorial e Hospitalar, totalizando R\$ 661.060.633,29 e representando 36,15\% dos repasses federais. Dos aproximadamente 17,5\% dos repasses federais restantes, destacam-se os blocos: Vigilância em Saúde com um total de R\$ 59.261.508,82, Serviços Hospitalares com um total de R\$ 34.244.396,53 e Assistência Farmacêutica com um total de R \$ 24.811.737,99, representando 3,24\%, 1,87\% e 1,35\% do total, respectivamente.

\section{CONSIDERAÇÕES FINAIS (ou Conclusão)}

De 2010 a 2015 evidenciou-se um aumento das transferências federais para os municípios da macrorregião Sudoeste da Bahia, mesmo se considerada a redução encontrada no ano de 2015. Em relação a participação das esferas de financiamento, nota-se uma gradual 
diminuição da participação da esfera federal em detrimento à esfera municipal, o que condiz com o princípio de descentralização do SUS.

Os blocos de financiamento são fundamentais para a gestão do SUS. O bloco de Atenção Básica, por sua vez, representa a maior fonte de transferências federais para os municípios da macrorregião. Tal fato, indica um movimento no sentido de estruturar a atenção básica no país, ao lado de um sistema de média e alta complexidade, o qual representou a segunda maior fonte de repasses para estes municípios.

A saúde deve ser uma prioridade de gasto, independentemente da conjuntura política e econômica. Assim, um estudo detalhado da organização e funcionamento do financiamento do Sistema de Saúde é essencial para a permanência e a continuidade do sistema como também para assegurar a evolução dos avanços já conquistados.

\section{REFERENCIAS}

BRASIL. CONSTITUIÇÃO (1988). Emenda Constitucional n 95 , de 15 de novembro de 2016. Altera o Ato das Disposições Constitucionais Transitórias, para instituir o Novo Regime Fiscal, e dá outras providências. Lex: legislação federal e marginalia. 2016.

BRASIL. MINISTÉRIO DA SAÚDE. Gabinete do Ministro. Portaria n ${ }^{\circ}$ 3992, de 28 de dezembro de 2017. Altera a Portaria de Consolida o $\mathrm{n}^{\circ}$ 6, de 28 de setembro de 2017, para dispor sobre o financiamento e a transferência dos recursos federais para as ações e os serviços públicos de saúde do Sistema Único de Saúde., de 29 de janeiro de 2007. Diário oficial da União. Dez 2017.

CENTRO DE ESTUDOS ESTRATÉGICOS DA FIOCRUZ. 2018 [online]. Portaria do Ministério da Saúde que dá autonomia a gestores locais desestrutura o SUS. Homepage: http://cee.fiocruz.br/?q=portaria-do-ministerio-da-saude-que-da-autonomia-a-gestores-locaisdesestrutura-o-sus

MAZON LM, COLUSSI CF, SENFF CO, FREITAS SFT. Execução financeira dos blocos de financiamento da saúde nos municípios de Santa Catarina, Brasil. Saúde Debate, 42(2): 38-51, 2018.

PAIM J, TRAVASSOS C, ALMEIDA C, ET AL. The Brazilian health system: history, advances, and challenges. Lancet, 377(9779):1778-1797, 2011.

PIOLA SF ET AL. Os efeitos da emenda constitucional 29 na alocação regional dos gastos públicos no Sistema Único de Saúde no Brasil. Ciência \& Saúde Coletiva, 21(2):411-421, 2016.

TELES AS ET AL. Blocos de financiamento: transferências federais para o estado da bahia. Rev. Saúde.Com, 12(2): 542-550, 2016. 